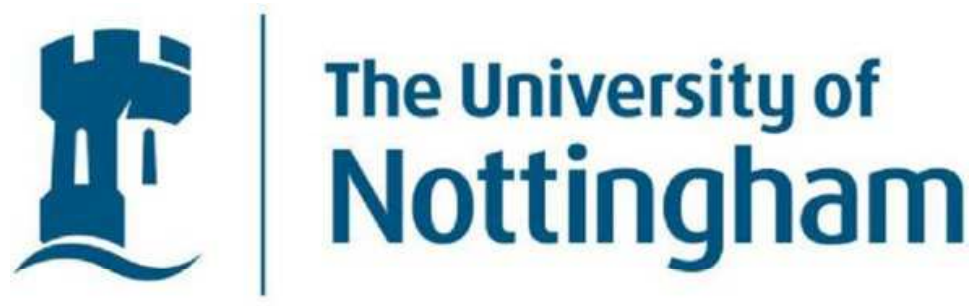

UNITED KINGDOM $\cdot$ CHINA $\cdot$ MALAYSIA

Discussion Papers in Economics

Discussion Paper No: 12/07

House Prices, Home Equity and Health

b y

John Gathergood and Eleonora Fichera

December 2012 


\title{
HOUSE PRICES, HOME EQUITY AND HEALTH
}

\author{
By \\ Eleonora Fichera* and John Gathergood ${ }^{\dagger}$ \\ * Institute of Population Health, University of Manchester \\ + School of Economics, University of Nottingham
}

\begin{abstract}
Home equity has a strong impact on individual health. In UK household panel data home equity lowers the likelihood of home owners exhibiting a broad range of medical conditions. This is due to increased use of private health care, reduced hours of work and increased exercise. Home equity, unlike income, does not increase risky health behaviours such as smoking and drinking. Home equity is highly pro-cyclical. The positive health effects of home equity gains on home owner health over the business cycle offset the negative effects of labour market conditions and work intensity as shown in US data by Ruhm (2000).
\end{abstract}

Keywords: health, wealth.

JEL Codes: I10, I13

Correspondence: john.gathergood@nottingham.ac.uk 


\section{Introduction}

The rapid house price increases in many countries during the early-2000s followed by large declines during the recent recession have provoked much interest in the impact of home equity on household activity and welfare ${ }^{1}$. Exploiting local house prices as an exogenous measure of home equity in UK individual-level panel data, we show that home equity gains yield large and positive effects on home owner health. These effects occur through investments in private healthcare, reduced hours of work and increased leisure plus exercise. We replicate the negative impact on health of local labour market conditions, proxied by the local unemployment rate, as shown in US data by Ruhm (2000, 2003, 2005) and compare these in magnitude with home equity effects. The positive health effects of home equity (which is pro-cyclical) on home owner health are at least as large as - and offset - the negative health effects of upturns in labour market conditions (which are also pro-cyclical).

Understanding the causal links between economic resources and health (which is assumed to be a normal good as in Grossman, 1972) is a central issue in the health economics literature (Deaton and Paxson, 1999; Marmot and Bobak, 2000). A reverse causality may also exist (Smith, 1999) or the positive relationship might be explained by additional factors such as family background or genetics (Currie and Stabile, 2003; Dehejia et al, 2004; van den Berg et al., 2006). Previous studies have used exogenous changes in economic resources such as lottery wins, inheritances or estimated income shocks to measure the causal relationship between wealth and health (Ettner, 1996; Meer et al., 2003; Lindahl, 2005; Gardner and Oswald, 2007; Michaud and van Soest (2008); Adda et al, 2009; Apouey and Clark, 2011;

\footnotetext{
${ }^{1}$ Including household consumption and saving (Campbell and Cocco, 2007; Disney et al., 2010; Attanasio et al., 2011), indebtedness (Hurst and Stafford, 2004), educational choices (Lovenheim, 2011; Lovenheim and Reynolds, 2011) rates of childbirth (Lovenheim and Mumford, 2010), demand for long-term care insurance (Davidoff, 2010) and divorce (Farnham et al., 2011).
} 
Kim and Ruhm, 2012). ${ }^{2}$ Typically these studies find no, or only very weak, effects of wealth on individual physical health.

Examining the effect of home equity on health is of particular interest for many reasons. Whereas lottery wins or inheritances are small components of average household wealth, home equity is one of the largest components of wealth for most households, especially in the United Kingdom (Banks et al, 2003) ${ }^{3}$. Moreover, in the period we analyse, from the early 1990 s to late 2000 s, financial liberalisation lead to home equity becoming a highly liquid form of household wealth ${ }^{4}$. In addition, there is considerable variation in the magnitude of house price movements across households both geographically and over time ${ }^{5}$. Also, by using local house price measures we can exploit exogenous variation of home equity wealth across individuals by their locality of residence.

Importantly, house prices exhibit pro-cyclical business cycle dynamics, illustrated for the UK in Figure $1^{6}$. Home equity effects on individual health arising from house price

\footnotetext{
${ }^{2}$ An additional strand of the literature exploits changes in public policy as a source of exogenous variation in income or wealth, as in Case (2004), Snyder and Evans (2006) and Frijters et al. (2005). Adda et al. estimate exogenous movements in income using the decomposition technique developed by Meghir and Pistaferri (2004).

${ }^{3}$ The home ownership rate in the United Kingdom is approximately 75\%. Banks et al. (2003) estimate that home equity accounts for $60 \%$ of household financial wealth among households in the United Kingdom.

${ }^{4}$ The Bank of England estimates that in the mid-2000s the amount of housing equity withdrawn by UK households via mortgage refinancing or downsizing averaged between 6 and 10\% of post-tax income (Reinold, K., 2011). The relationship between house price movements and consumer spending is analysed by Campbell and Cocco (2006), Disney et al (2010) and Attanasio et al. (2011).

${ }^{5}$ Average house prices increased (in real terms) by $74.3 \%$ between 1982 and 1989, then fell by $34.7 \%$ between 1989 and 1995, then increased by 148.5\% between 1995 and 2007 and have since fallen by $21.4 \%$ since 2007. There is also much regional variation in house price movements across the business cycle. For example, in 1994 prices in Greater London fell by $40 \%$ while prices in Scotland rose by $9 \%$. Source: Halifax Building Society house price index (authors' calculations).

${ }^{6}$ Figure 1 illustrates the business cycle dynamics of UK Gross Domestic Product (GDP) and House Prices. Details of the data sources are provided below the Figure. House price movements are strongly pro-cyclical: the correlation coefficient for the deviations from trend of both series is 0.60 . House prices are also more volatile than GDP. The percentage standard deviation from trend in house prices expressed as a percentage of the
} 
movements over the business cycle might, therefore, offset the counter-cyclical effect on health from economic upturns shown in US data by Christopher Ruhm (Ruhm 2000, 2003, 2005). Ruhm shows that upturns in labour market over the business cycle, proxied by the local unemployment rate, lead to worsening health among the working population ${ }^{7}$. He shows that economic upturns are associated with increased hours of work, longer commutes, less time at leisure and less physical activity, increased smoking and alcohol consumption, poorer diets and weight gain (Ruhm, 2000). Ruhm's interpretation of his findings is that economic upturns increase the opportunity cost of time and cause workers to substitute away from healthy activity and health production towards work activity and forms of stress relief such as smoking and drinking. There is also evidence that mortality among the non-working population is pro-cyclical for reasons unrelated to an individual's opportunity cost of time (Miller et al., 2009).

However, we show that pro-cyclical home equity gains for home owners generate positive health effects through increased purchases of health care, reduced hours of work (as leisure, like health, is a normal good) and increased recreational exercise. Home equity gains do not generate the substitution effect of encouraging work and unhealthy work-related behaviours and activities; we find no effect on smoking and alcohol consumption. However, we find some evidence for negative health effects for renters, for whom house price increases which result in increased rental prices or increased prices of prospective future housing purchases encourage increased work and/or negative health effects associated with reduced leisure activity.

percentage standard deviation in trend in GDP is $376.3 \%$. Using a linear trend the equivalent statistics are 0.73 and $342 \%$.

${ }^{7}$ In his analyses this is evidenced in higher mortality rates, including those arising from heart and respiratory conditions (Ruhm, 2000) and also increases in ill health among the working population, in particular ill health related to ischemic heart disease and back disorders (2003). 
The UK is a particularly appropriate context for studying this issue as UK house prices are pro-cyclical over multiple recent business cycles, as illustrated in Figure 1. Plus in our data we can exploit two house price 'booms' and 'busts'. Our sample period runs from 1991 to 2009 and spans both the housing market upturn and crash of the early 1990s and the sustained housing market boom of the early 2000s before recent house price declines observed post $2007^{8}$. We estimate the impact of house price movements on a full range of physical medical conditions at the individual level using the British Household Panel Survey (BHPS $)^{9}$. We do not use a self-assessed health measure due to concern over its reliability (Crossley and Kennedy, 2002). We use local level house prices based on sales data instead of self-assessed house prices which may be endogenous to individual health status ${ }^{10}$.

Although local house price movements are exogenous to individual households they are in part driven by local economic conditions which are likely to impact upon individual health other than through home equity effects. We condition our estimates on locality and time effects by incorporating local-level and time dummies into our econometric model. We also estimate the impact of local house price movements on the health of renters in our

\footnotetext{
${ }^{8}$ Our data includes the sharpest period of house price declines through 2008. Interviewing for the survey begins on 1 September each year. The majority of respondents are interviewed in the final quarter of the calendar year. Between quarter 42007 and quarter 42008 house prices fell by 14.7\% in real terms in the U.K. Source: Halifax Building Society house price index (authors' calculations).

${ }^{9}$ The BHPS is also used by Apouey and Clark (2011) and Gardner and Oswald (2007) though we are the first to present results for physical health conditions. One attraction of the BHPS is that it asks respondents about a broad range of medical conditions (as well as containing self-assessed health measures which we do not use) and also contains detailed information on housing, geographic location and a broad range of socio-economic characteristics such as income and labour market status. It also has the attraction of being a panel survey which employs a following rule such that it remains representative of the UK population as a whole throughout the 18 waves currently available.

${ }^{10}$ Crossley and Kennedy (2002) examine the consistency of self-assessed health status in a survey of Australian individuals in which a random sub-sample of respondents answered a self-assessed health status question both before and after a set of health-related questions. They find $28 \%$ of respondents changed their reported health status after answering the health-related questions. They also find the consistency of individual responses is statistically significantly related to socio-economic characteristics.
} 
sample to test whether house prices proxy for local economic conditions. Renters experience the same labour market and macroeconomic conditions as owners without experiencing the direct wealth gains or losses due to house price movements. We also show that home moving activity between low house price and high house price areas does not bias our results.

We show many new results. Firstly, we show that home equity gains have positive effects on home owners' health. We show increases in home equity cause a reduction in likelihood of home owners exhibiting a wide range of medical conditions including related to arthritic and rheumatic conditions, chest and respiratory conditions, heart and blood pressure problems, skin problems, diabetes, epilepsy and symptoms of anxiety or depression.

Secondly, we can replicate Ruhm's findings in our UK data. We estimate the effects of local labour market conditions using the local unemployment rate as a measure of the state of the local labour market. In keeping with Ruhm's findings we find lower local unemployment rates are associated with worse health due to the impact of strong local labour market conditions on hours of work and risky health behaviors such as smoking. However, the main difference in our results is that we show that home equity gains act to offset these labour market effects over the business cycle for home owners as home equity gains are positively correlated with strong local labour market conditions.

Thirdly, we show the health effects of home equity are stronger for younger individuals and for women. Importantly, we show that younger households who most strongly show worsening in health due to upturns in the local labour market and associated increases in work and risky health behaviours are also the group who exhibit the positive strongest health effects of home equity gains.

Fourthly, we show various channels by which home equity translates to improved health, some of which are the same channels by which local labour market upturns translate to worse health outcomes. First, home equity raises the likelihood that an individual will 
purchase of private health care. In our UK context private health care coverage is relatively rare, especially in comparison with the US, but home equity gains raise the likelihood of individuals purchasing private medical coverage. Second, and analogous to Ruhm's analysis, home equity lead to reduced hours of work (for women), plus increases in recreational leisure, sport and exercise. We show leisure time and recreational activity are lower when the unemployment rate is lower (as in Ruhm's analysis), but increase with home equity.

Fifthly, we show that home equity gains do not have strong effects on risky health behaviours, specifically smoking and drinking. This result contrasts with the effects of labour market upturns which increase these risky behaviours in the working age population, and also contrasts with results from prior studies using UK data based on lottery wins (Apouey and Clark, 2011) and income shocks (Adda et al., 2009) which show both cigarette consumption and alcohol consumption increase with higher values of lottery wins and greater income shocks. We explain the differences between our results and these studies, and then discuss the implications of our results for understanding health inequality and the business cycle dynamics of health.

To our knowledge ours is the first study to examine the impact of home equity gains on health. Recent related studies have shown the effects of foreclosure and mortgage delinquency on mental health. Currie and Tekin (2011) show that in US states where foreclosures are most common rates zip codes with the highest foreclosure rates also have the highest rates of hospital admissions for stress-related conditions and also the highest suicide rates. Gathergood (2012) uses UK data and shows that individuals delinquent on mortgage payments exhibit much higher levels of psychological stress or anxiety, and that causality runs from financial problems to mental health. Our study differs from these in that we examine the impact of home equity wealth across the whole population of home owners (instead of home equity 'disasters' such as foreclosure which affect only a subset of home 
owners) over a longer period and on the full range of physical medical conditions and a broad set of health related behaviours.

\section{Health Data and House Price Data}

The BHPS is an annual survey of each adult member (16 years of age and older) of a nationally representative sample of more than 5,000 households, comprising a total of approximately 10,000 individual interviews. Major topics in the survey are household composition and demographics, the labour market, income and wealth, housing, health and socio-economic information. The same individuals have been re-interviewed in successive waves and, if they split-off from original households, all adult members of their new households have also been interviewed. Children are interviewed once they reach the age of 16. The sample is representative of the population of Britain. We use are 18 waves of data available from 1991 to $2008^{11}$.

We use all the available data for this study and our whole sample comprises 155,396 individual-year observations for household heads plus his/her spouse. Summary statistics for the whole sample are contained in Table 1. In each wave the BHPS contains a health module. In that module each respondent is asked to identify the health problems and disabilities they are currently suffering from a list of 15 health conditions on a show-card shown to them by the interviewer, omitting a non-specific category of 'other health problems' from our analysis.

From these responses we construct two measures of health: a series of $1 / 0$ dummies for each health condition and a count measure (taking a value 0-14) based on the number of

\footnotetext{
${ }^{11}$ From 2009 the BHPS is incorporated into the new 'Understanding Society' household panel survey, which will become the world's largest household panel comprised of approximately 100,000 respondents. The BHPS sample is incorporated into the Understanding Society survey from Wave 2 (2010-11) onwards. At the time of writing, these data are not yet available.
} 
individual health conditions reported by the respondent (data on cancer and stroke are only available since 2001). Table 2 provides summary statistics for the full range of physical health conditions. On average respondents report suffering from 1.18 health conditions (the maximum observation is 11). The notes accompanying the table list the full description of each medical condition listed on the show-card shown to respondents. The most prevalent health conditions among respondents are 'arms, legs, hands, feet, back, neck' (31\%), 'heart, blood pressure' (19\%) and 'chest, respiratory' (13\%).

We match into the BHPS local level house price data derived from house price sales. We use the Halifax county-level house price index for the 64 counties of England and Wales provided by Halifax Bank of Scotland (now part of the Lloyds banking group), the UK's largest mortgage lender ${ }^{12}$. These data are available for the whole period under analysis, 1991 - 2008. The Halifax index comprises standardised house prices which reflect the sale price of a medium-sized family home in each county in each year. Throughout we adjust all financial variables to 2000 prices using the Retail Prices Index. We also match into the BHPS local level registry unemployment data provided by the Office for National Statistics (ONS), also at the county level.

To establish a correlation between housing wealth and health exists in our data in Table 3 we show the cross-section health-wealth relationship for housing wealth and health among home owners in OLS regression estimates from pooled cross-sections of our sample of owners. In the first column the count measure of number of medical conditions takes a value between zero and 14, in the subsequent columns the dependent variable is a $1 / 0$ dummy which indicates whether the individual exhibits that medical condition. For these estimations

\footnotetext{
${ }^{12}$ The Halifax house price index is the UK's longest running house price index based on the largest available sample of sales data for the duration of the BHPS survey period. A similar index based on a smaller sample of sales is provided by the Nationwide building society. A non-standardised sales price index based on all house sales is provided by the Land Registry for 1997 onwards. Whe obtain near-identical results when using either of these alternative indices.
} 
and throughout the paper we use a linear probability model due to the ease of interpretation of the estimated coefficients.

These estimates do not show a causal relationship due to the endogeneity of housing wealth to health, instead they establish that a correlation exists in our data. We include a set of socio-economic control variables plus time dummies and county dummies. The coefficient on housing wealth is statistically significant at the $1 \%$ level in 10 of the 14 models and in each case has a negative coefficient. Hence the 'health wealth' gradient is noticeable in the probabilities of individuals in our sample exhibiting a wide range of medical conditions. We do not discuss the magnitudes of the coefficients here as the estimated values cannot be interpreted as causal. At a basic level, these results motivate our analysis by showing a negative correlation between housing wealth and a broad range of health problems in our data.

\section{Econometric Model}

We estimate the effect of home equity on individual health using the following econometric model. An equation to estimate the impact of home equity and local unemployment on individual health among home owners takes the form:

$$
\text { health }_{i c t}=\alpha+\beta_{1} H_{c t}+\beta_{2} U_{c t}+\beta_{3} X_{i c t}+\varphi_{i}+\theta_{c}+\psi_{t}+\varepsilon_{i c t}
$$

where $i$ denotes an individual, $c$ denotes county of residence, $t$ denotes year. The variable $H_{c t}$ is the average house price at the county level in each year, $U_{c t}$ is the local unemployment rate at the county level in each year and $X$ is a set of socio-economic characteristics and control variables. The dependent variable health $h_{i c t}$ represents measures of individual health. The key identifying assumption in Equation 1 is that that house price 
variation across counties over time is, conditional on county fixed effects $\theta_{c}$ and year fixed effects $\psi_{t}$ plus the vector of time-varying control variables $X_{i c t}$, the local unemployment rate $U_{c t}$ and time-invariant individual characteristics captured by the individual fixed effects $\varphi_{i}$, exogenous to individual health. We estimate the models using (within) fixed effects estimation and use a linear estimator throughout. As the house price variable and unemployment variable are defined at the local level standard errors are clustered at the county level.

To interpret the coefficient $\beta_{1}$ as representing the impact of home equity on health requires that the estimated impact of house prices on health is not attributable to omitted variable(s) which might drive both house prices and health for which house prices might proxy ${ }^{13}$. Equation 1 includes individual fixed effects, county fixed effects and time fixed effects which in part capture individual, locality and time related heterogeneity. A more robust approach is to incorporate renters into the estimation strategy. Renters experience the same local economic conditions as home owners but do not experience direct wealth gains and losses from house prices. If renters experience indirect wealth gains or losses from changes in the price of housing they intend to buy in future then these gains and losses are in the opposite direction to those experienced by current owners. The difference between estimated coefficients for renters and owners can be interpreted as the direct effect of housing wealth on health. Therefore, we modify Equation 1 as follows:

health $_{i c t}=\alpha+\beta_{1} H_{c t} * O_{i c t}+\beta_{2} H_{c t} * R_{i c t}+\beta_{3} O_{i c t}+\beta_{4} U_{c t}+\beta_{5} X_{i c t}+\varphi_{i}+\theta_{c}+\psi_{t}+\varepsilon_{i c t}$

where $O$ is a 1/0 dummy variable indicating the individual is a home owner and $R$ is a 1/0 dummy variable indicating the individual is a renter. In our (within) fixed effects

\footnotetext{
${ }^{13}$ For example, if local house price increases are due to better provision of local public health services then our estimates would suffer omitted variable bias.
} 
estimation the coefficient on the $O$ dummy which enters separately from the house price terms captures the difference in health associated with home ownership. If the coefficients on the two county house price terms both positive and equal (the estimated impact of county house prices on the health of owners and renters is identical) then we would conclude that county house prices proxy for unobserved local conditions. If they are both zero, we would conclude house prices have no impact on health. We test these directly.

Our interpretation of the coefficient $\beta_{1}$ as representing the impact of home equity on health would also not hold if improvements in health cause home owners to move to counties with higher house prices. For home owners who do not move county, changes in county level house prices are evidently not caused by changes in individual health (though this would not be the case for self-reported individual level house prices if, for example, improving health enables individuals to undertake more home improvement or consider themselves better able to prepare their homes for sale and so be more optimistic about the market value of their home $)^{14}$. For home owners who move between counties, a reverse causality may exist if moving to a higher (lower) house price county is caused, for example, by improving (worsening) health, for example improving health allowing an individual to take a more demanding job in a county with stronger local labour market conditions where demand for housing, and hence house prices, are higher.

We show that this form of moving activity caused by changes in health, which would bias our results does not occur among individuals in our sample. We estimate models for the likelihood of home owners moving home between waves either i) within-or-between counties or ii) from a lower (higher) house price county to a higher (lower) house price county against a set of 1/0 dummy variables which take a value of one if an individual recovers from

\footnotetext{
${ }^{14}$ Survey questions which ask individuals to estimate the value of their home commonly take the form of: 'what do you think you would get for your home if you sold it today?' If individuals with better health anticipate being more able to prepare their homes for market then estimated sale prices will be higher among healthier owners.
} 
(experiences the onset of) a medical condition and a value of zero otherwise. Results are shown in Table A1 in the appendix. In only very few cases are the estimated coefficients on the dummy variables statistically significant at the 5\% level or lower and, in those cases, the estimated coefficient has an opposite sign to that which would bias our results. Also, in the next section we show that our results are unaffected by omitting movers from our estimation sample.

\section{Results}

\subsection{Health Outcomes}

Estimates of Equation 1a are shown in Table 4. Results show home equity leads to a lower likelihood of owners exhibiting a broad range of medical conditions. The coefficient on the owner house price term in the model with the 'count' measure as the dependent variable is negative, statistically significant at the $1 \%$ level and has a value of -0.158 , implying that a $£ 100,000$ increase in local house prices for a home owner is associated with, on average, a 0.158 point fall in the number of medical conditions exhibited by home owners. Statistically significant coefficients at a $1 \%$ level of significance are estimated for the owner house price term (row 1) for eight specific conditions, including the four most prevalent among respondents in our data - 'arms, legs, hands, feet' (31\% of the sample), 'heart' (19\%), 'chest' $(13 \%)$ and 'skin' (11\%) - as well as 'diabetes', 'alcohol', 'epilepsy' and 'anxiety', with a weakly significant coefficient on owner house price term for the 'stroke' outcome, significant at the $5 \%$ level only.

Health conditions for which the estimated coefficients on the home owner county house price variable are negative and statistically significant at the $1 \%$ level also show, in all but one case (anxiety), statistically different values from the coefficient on the renter house price variable. For most of the individual medical conditions with positive home equity 
effects for owners, the renter house price term is not statistically significantly different from zero ('arms, legs, hands, feet', 'chest', 'heart', 'diabetes', 'alcohol', 'epilepsy'), the exceptions being 'skin' and 'sight' which show positive coefficients and also 'anxiety'.

In the case of 'anxiety', the coefficient on the renter house price term is actually weakly negative. This suggests there might be some positive impact of rising local house prices on the psychological health of renters and that the means by which home equity wealth effects impact upon owners and renters in opposite directions do not apply to psychological health. In this case the renter house price term is again statistically significantly different from the owner house price term.

We show results for 'cancer', even though the estimated coefficients on the house price or unemployment variables are never statistically significant ${ }^{15}$. This illustrates the unresponsiveness of cancer to short-term home equity changes, an unsurprising result and the same as that in Ruhm $(2000,2003)$ who finds cancer is unresponsive to the local unemployment rate, a finding we also replicate here.

The pattern in the coefficients on the unemployment rate variable in our results here is similar to that in Ruhm's studies: high unemployment is associated with lower likelihood of exhibiting an arthritic / rheumatic conditions and stroke, but unlike Ruhm's analysis we find no effects for heart conditions. We also find effects on skin disease and diabetes ${ }^{16}$. Home equity impact on a much broader range of medical conditions compared with those which are responsive to the local unemployment rate.

\footnotetext{
${ }^{15}$ Results are also not shown for 'hearing', 'stomach' or 'migraine' as in each of these cases the estimated coefficients on the house price and local unemployment rate variables were statistically insignificant.

16 Among Ruhm's studies, the most comparable to ours using individual level microdata on specific medical conditions is Ruhm (2005) (as opposed to state level mortality data used in Ruhm, 2000). There, he shows higher local unemployment is associated with a lower likelihood of back disorders (part of the 'arms, legs, hands, feet, back, or neck (including arthritis and rheumatism)' variable in our data), stroke (as in our data) plus also heart disease and diseases of the central nervous system. We do not find the same result for heart disease in our data.
} 
We can be confident these results are not attributable to a reverse causality which would arise if improvements in health causing individuals to move to higher house price counties. As discussed in the previous section results in Table A1 show there is no evidence for this type of moving activity in our data. However, for completeness in Table A2 we restrict the sample to individual-year observations for individuals who do not move across counties between waves ( $4.18 \%$ of the sample). The estimated coefficients are near-identical to those shown in Table 4.

The implied magnitudes of the estimated effects of local house prices and unemployment on health conditions are shown in Table 5. To indicate of the economic significance of the estimated coefficients, the statistically significant coefficients on the variables in Table 4 are shown in this table evaluated against the prevalence of each medical condition in the sample for the whole-sample one standard increases in local house prices (approximately $£ 49,000)$ and the local unemployment rate (2.88 percentage points). These calculations show a one standard deviation increase in local house price cause close to a $6.7 \%$ reduction in the number of health conditions as measured by the count variable.

Among the specific health conditions for which the estimated coefficients are statistically significant at the $1 \%$ level, the size of the implied effect ranges from a $21 \%$ reduction in the likelihood of exhibiting an anxiety related condition ('anxiety') to a $4 \%$ reduction in the likelihood of exhibit an arthritic/rheumatic condition ('arms, legs, hands, feet). The effect is larger for 'stroke', but the coefficient is less well defined. Most of the affected health conditions show percentage reductions in the likelihood of exhibiting a condition of more than $10 \%$, showing home equity effects on home owner health are sizable across a range of conditions.

Similar calculations for the impact of the local unemployment rate on health conditions show large effects $(>10 \%)$ for 'stroke', 'diabetes' and 'skin' with a much smaller 
effect, approximately 3\%, for 'arms, legs, hand, feet'. The lower overall effect of a one standard deviation increase in the unemployment rate on the 'count' measure (approximately $3.4 \%$ compared to $6.7 \%$ for a one standard deviation increase in house prices) is mostly attributable to the narrower range of health conditions affected by local unemployment rates. However, for specific conditions these calculations show the health effects of local unemployment are very similar in magnitude to the health effects of local house prices. For 'arms, legs, hands, feet', 'skin' and 'diabetes' the effects of house prices and unemployment are very similar in size. By contrast, for 'stroke' there is a large negative effect from high local unemployment but no statistically significant effect from house prices.

These results show that for home owners the negative business cycle health effects of labour market upturns are offset by the positive effects of home equity. The strong positive effects of home equity on a broad range of health outcomes show home equity to be an important pro-cyclical driver of good health among home owners, larger in magnitude than the negative effects labour market tightness and associated work intensity. However, this is only the case for home owners who benefit from home equity gains. For renters, we observe some negative health effects from higher local house prices in which case local house prices are a pro-cyclical driver of poor health in addition to the pro-cyclical negative health effects arising from labour market activity.

These results raise the question of why some health conditions are responsive to home equity gains but not local labour market conditions, with the exception of 'stroke' which shows a strong response to local labour market conditions but no response to home equity. One possibility raised in the literature is that housing wealth gains impact upon physical health via their effect upon psychological stress and / or behavioural patterns associated with 
psychological stress ${ }^{17}$. However, while home equity has a strong impact on 'anxiety' for owners, local house prices also decrease anxiety for renters (unlike other health outcomes). This suggests results for other health outcomes do not indicate physical symptoms of psychological stress. We investigate the mechanisms by which home equity impacts these health outcomes in more detail below.

\subsection{Analysis of Effects by Gender and Age}

In this section we investigate how the estimated effects of home equity on homeowner health differ between men and women and across younger and older age groups. These results are of particular interest because in Ruhm's analysis the negative health effects of local labour market conditions are concentrated on working age males, the group most active in the labour market. Ruhm finds weaker effects for older (i.e. retired) workers, for whom the opportunity cost of time is unlikely to change when labour market conditions improve as they are no longer in the labour force, though they might suffer some externalities from local economic upturns, such as increased pollution, inward migration and demand on public services when economic conditions improve.

By contrast, older individuals might be the group most likely to show health benefits from increased home equity. Older households typically have higher levels of home equity and are unlikely to purchase larger houses in future so home equity gains are more likely to be permanent for this group than among younger households. It may be the case that our

\footnotetext{
${ }^{17}$ Brunner (1997) provides evidence that the reduction in psychological stress associated with increases in economic resources and social elevation reduce the likelihood of cardiovascular and immunity-related (e.g. respiratory) disease, which might in part explain the outcomes for 'chest' and 'heart' ${ }^{17}$. Other studies provide mixed evidence for this hypothesis. Adams et al. (2003) find a significant wealth gradient in the incidence of some mental, chronic and degenerative conditions. They attribute these results to a combination of direct causal links and common unobserved behavioural or genetic factors. Schwandt (2011) uses U.S. stock market fluctuations as wealth shock and shows a heterogeneous effect across health conditions. The most pronounced effects are found for the incidence of high blood pressure, smaller effects for heart conditions and stroke. Of course, increased wealth also impacts on health production, prevention and treatment directly, though the mechanisms for these are many and various (see for example, the extended discussion in Adams et al., 2003).
} 
results shown in the previous section mask important heterogeneity in the response of older and younger individuals, males and females to home equity and labour market conditions.

Separate estimates for older and younger individuals are shown in Table 6. We separate the sample into older individuals age 60 or above and younger individuals aged between 18 and 59 and estimate separate regression models for each health outcome for each group. They key difference between these groups is their participation in the labour market. The employment rate among the younger group is $72 \%$ compared with $11 \%$ among the older group. For simplicity of exposition we show here only estimated coefficients from regressions for each medical condition outcome plus the 'count' measure, alongside subsample means for each condition and the implied percentage change in the likelihood of an individual exhibiting each outcome for a one standard deviation change in home equity and the unemployment rate. In each case where the coefficient on the home owner local house price term was statistically significant at the $5 \%$ level or lower, the coefficient was also statistically different from the coefficient value on the renter house price term in the regression.

Home equity effects and local labour market effects on health occur more strongly and for a wide variety of medical conditions among individuals of working age. Among the older group local labour market affects only 'anxiety' and home equity effects are limited to 'anxiety', 'skin' and 'arms, legs, hands, feet' only, whereas among the younger group statistically significant effects present for all the medical conditions with statistically significant estimated coefficients in the whole sample estimates in Table 5 plus also 'stomach' for local labour market conditions. Hence results show working age individuals, whose health is most affected by local labour market conditions, also show the strongest health responses to home equity. However, as in Table 5, the results in Table 6 show that home equity effects are seen on a broader range of medical conditions for both older and 
younger individuals compared with the impact of local labour market conditions, again particularly so for younger individuals.

Results by gender are shown in Table 7. Again, for simplicity of exposition we do not show the full regression output but instead Table 7 mirrors Table 6 in presenting estimated coefficients and standard errors on the home owner house price terms alongside sample means for each health measure and the implies percentage change in each health outcome from a one standard deviation increase in the house price. Also, we only report calculations for the coefficients and implied magnitudes from home equity as the implied magnitudes from the coefficients on the local unemployment rate were identical for men and women.

Results show the health effects of local house prices are in general a stronger for women compared with men. Women exhibit a broader range of health outcomes which improve with home equity compared with men and, notably, there is no impact of higher house prices on 'anxiety' for men but strong reduction, close to $30 \%$, for women. There are some cases in which effects are evident for male health but not female health: for the 'alcohol' category results show an effect for men but not women and for the 'arms, legs, hands, feet' the magnitude of the implied effect is slightly higher for men.

Overall, results for the 'count' outcome show the coefficient on the home owner county house price term is larger for women and, although the mean number of health conditions exhibited by female home owners in the data is larger than that among male owners, the implied impact of a one standard deviation increase in house prices for female owners is nevertheless three times larger than that for male owners. We return to the question of why the estimated effects of home equity vary between older and younger, male and female individuals in our discussion of results for drivers of individual health below. 


\subsection{Investment in Private Medical Insurance}

One channel by which wealth effects from home equity impact upon individual health might be through purchase of higher quality healthcare which, in our UK context, is in the form of private medical insurance ${ }^{18}$. Basic healthcare provision in the UK is dominated by the publicly funded National Health Service (NHS) which is 'free at the point of use' to all UK residents.

Existing studies show private medical insurance is likely to improve individual health for a variety of reasons. Private hospitals are better equipped and hire more senior doctors (Propper et al, 2001). Treatment purchased privately is normally available faster with shorter waiting times (Besley et al., 1999). Most commonly, waiting times for one-off surgical procedures such as hip or knee replacements in the public system can be many months. Also, private waiting times for diagnostic examinations or scans (e.g. CT scans) for serious conditions for which the benefits of early treatment are large (e.g. cancer) are typically very short, whereas in the public system patients may have to wait a few weeks. In addition, private provision of 'soft' treatments such as physiotherapy and post-stroke rehabilitation is typically more extensive, as is provision of preventative care.

Private medical coverage also offers healthcare provision which makes it more likely that a patient will recover from a given condition sooner and with fewer on going complications. One key benefit of private medical insurance is access to newer, more effective drugs faster. Although NHS drug prescriptions are free all patients irrespective of medication type or $\operatorname{cost}^{19}$, official NHS prescription drug 'pathway' rules limit public prescribers to initial prescription of only lower-cost drugs (typically out-of-patent or

\footnotetext{
${ }^{18}$ The existing literature finds evidence for home equity effects on household consumption in general (Campbell and Cocco, 2006; Disney et al., 2010) and we might expect that, as a normal good, purchases of private medical insurance would also increase with home equity gains.

${ }^{19}$ Prescription medication prescribed by general practitioners in local surgeries carries a nominal charge of $£ 7.65$ per item with the option for individuals to the waive per-item charges by pre-paying a fixed annual charge of $£ 104$.
} 
generics) with conditional access to the latest drugs only once lower-cost alternatives have proved ineffective. Also, the public system is slow to approve the introduction of newer, more expensive alternatives. Private medical insurance plans typically entitle the holder to faster access to newer and more effective drugs not yet available on the public system.

We estimate the impact of home equity on purchases of private medical coverage by individuals using the same econometric model as that used for health outcomes based on equation 1a. The BHPS includes a question asked to all individuals from 1996 onwards about whether they covered by private medical insurance (either in their own name or through another family member) with a follow-up question on whether this insurance is paid for by the holder directly or paid for by the employer. We create a $1 / 0$ dummy indicator for each individual covered by private medical insurance paid for directly by the policy holder. In our data approximately $5 \%$ of the sample is covered by private medical insurance.

Results in Table 8 show home equity increases the likelihood of private medical coverage for home owners. Results in the first column for the whole sample show the owner house price variable has a positive coefficient, statistically significant at the $1 \%$ level. The coefficient on the renter house price variable is statistically insignificant, and the test for the equivalence of the coefficients on the owner and renter county house price variables rejects their equivalence at the $1 \%$ level. The coefficient on the local unemployment rate variable is also statistically insignificant.

The magnitude of the coefficient of the owner county house price variable of 0.02 , evaluated against a baseline mean rate of holding private medical insurance in our sample of $5 \%$, implies a one standard deviation increase in county house price (approximately $£ 50,000$ ) increases the likelihood of a home owner holding private medical insurance by $20 \%$. This provides evidence that one mechanism by which home equity impacts on individual health is via increased health care purchases, though it is very unlikely that this might explain the high 
average effect of home equity gains given the small proportion of the sample who make use of private health care.

In subsequent columns estimates are shown for separate samples of men and women, younger and older individuals. Results show little difference in the estimated coefficient on the owner house price term for men and women, but a large difference for young and old. The estimated coefficient on the owner house price term for young individuals is twice as strong as that for the whole sample, whereas the estimated coefficient on the owner house price term for older individuals is zero. The coefficient value of 0.40 for the younger group implies the likelihood of purchasing module insurance for a young owner experiencing a one standard deviation increase in home equity is $40 \%$. This stronger effect for younger individuals is in keeping with the stronger impact on home equity gains on the health of the young found in the previous section.

\subsection{Hours of Work and Leisure Activity}

An alternative mechanism by which home equity gains may impact upon individual health is by leading individuals to reduce hours of work and increase physical exercise and leisure activity. Reduced leisure and increased work intensity is, in Ruhm's analysis, central to worsening health during economic upturns due to direct effects on health from longer hours of work but also indirect effects through accidents, long commutes, less investment in healthy activities, more 'eating out' plus more cigarette and alcohol consumption.

What mechanisms can explain the effect of house prices on health through working hours and physical activity? One channel could be that reduced work hours lead to increases in sleep (Biddle and Hamermesh, 1990) which in turn is thought might be linked to lower rates of obesity and related conditions such as musculo-skeletal disorders and diabetes 2 
(Sparks and Cooper, 1997; Spivey, 2010). Edwards (2008) found that increased non-work time increases sleeping and socialising, which have positive health benefits.

A second channel could be through the increase in non-market leisure time making it less costly for individuals to undertake health-enhancing activities including physical exercise and home food production. Petersen and Pederson (2004) show that even small increases in physical exercise yield large benefits through the anti-inflammatory effects of physical movement. Williamson and Pahor (2010) show physical exercise impacts on a broad range of health outcomes including cardiovascular disease, respiratory illnesses, osterporosis and improve global functional capacity.

Courtemanche (2009) showed that shorter work hours reduce obesity via an increase in exercise and consumption of fast food and prepared processed foods. Also, if health production is time-intensive, the demand for both health and the inputs used to produce it are likely to rise when time prices fall (Grossman, 1972). There is evidence that higher time prices correlate with increased obesity (Chou et al., 2004) that in turn is one of the major risk factors for heart and circulatory diseases.

By this argument, home equity pure wealth effects on labour supply would offset the substitution effect of wage increases during economic upturns (assuming, as is common, that the substitution effect of a wage increase exceeds the income effect for the average worker). To examine this mechanism in more detail we estimate the impact of local house prices and the local unemployment rate on total hours of work among working individuals in our sample, active leisure time and physical work capability ${ }^{20}$.

Firstly, our data on total hours of work is taken from two BHPS questions which ask employed and self-employed individuals to state their 'usual hours of work per week' plus, separately, their 'typical overtime hours per week'. We estimate separate regressions for men

\footnotetext{
${ }^{20}$ Unfortunately, in our data we do not have consistent measures of diet and weight. Individuals are asked about their weight in two waves only, and the format of the question differs between the two waves.
} 
and women due to the likely different working choice contexts for men and women, with women typically being the second worker in a household's labour supply choice. In our sample the mean total hours of work per week for men is 43.9 hours and for women 31.1 hours.

Results for hours of work are shown in the first two columns of Table 9. For both men and women hours of work increase with lower local unemployment rates, but only for women do hours of work decrease with higher local house prices. However, the magnitude of each of these effects is small. The implied magnitudes of the responsiveness of hours of work to the unemployment rate for men and women are similar: a one standard deviation decrease in the local unemployment rate evaluated against mean hours of work in the sample causes hours of work for men to increase by $1.7 \%$ and for women by $1.5 \%$. For women a one standard deviation increase in house prices causes hours to decrease by $1.5 \%$. These magnitudes would not seem large enough to generate the strong effects on individuals health observed in earlier estimates for health outcomes.

Secondly, however, we examine the impact of home equity gains on the frequency of sport and exercise and find much stronger effects for women. The dependent variable in this case is constructed from three questions asked to all individuals in the BHPS about whether they 'plays sport or goes walking or swimming', 'works in the garden' and 'attends keep fit or yoga classes' at least once per week. We combine these questions to generate a single dummy variable for whether an individual answers 'yes' to at least one of these question. The mean in the same for women is 0.24 and for men 0.26 .

Results in Columns 3 and 4 show no impact of local unemployment rates on this variable, nor any impact of local house prices for men, but a strong effect for women. The magnitude of the estimated effect is much larger compared with the implied effects of home equity gains on hours of work. The coefficient on the home owner local house price variable 
evaluated for a one standard deviation increase in home equity against the sample mean implies a 9.4\% increase in the likelihood of a woman engaging in weekly exercise when house prices increase.

The absence of any effect for men alongside a strong effect for women suggests this is one explanation for the stronger responsiveness of health conditions to home equity for women compared with men found earlier in our results. In particular, those results showed a strong impact of home equity on the 'heart' outcomes (which includes problems relating to high blood pressure) for women but no statistically significant effect for men. This difference, particularly the element relating to management of blood pressure, might be explained by the difference found here in responsiveness of regular physical exercise among women to home equity but not among men.

Thirdly, and again in contrast to the hours of work results, we find sizeable impacts of home equity in reducing activity limiting health conditions. Within the health module, each individual in each wave of the BHPS is asked 'does your health in any way limit your daily activities compared to most people of your age', with the option of answering 'yes' or 'no. Among men 17\% answer 'yes' to this question and among women $21 \%$. The estimates in Columns 5 and 6 imply one standard deviation increases in home equity lead to $7.9 \%$ and $6.8 \%$ reductions in the likelihood of answering 'yes' to this question for women and men respectively.

These stronger results for the frequency or sport / exercise and individual physical capability show home equity has significant impact on physical condition and investment in physical health, particularly for women. The results for sport / exercise frequency in particular suggest the weak effects of local unemployment rates and house prices on total hours of work in our data might be attributable to individuals not varying their reported 'typical' or 'normal' hours of work over the business cycle, or alternatively reported hours of 
work not capturing working from home, additional evening work not considered as 'normal' working hours or other spill-overs of work into leisure time.

\subsection{Health Behaviours: Smoking Intensity and Social Alcohol Consumption}

Although our results show home equity leads to health improvements through increased purchase of health care and increased leisure and leisure activity, these might be offset in part if home equity gains also lead to an increase in risky health behaviours, the most common of which are smoking and alcohol consumption. The existing literature on the health effects of increased wealth presents evidence to suggest these are normal goods.

Adda et al. (2009) analyse the impact of permanent income innovations on individual health behaviours, estimating income innovations in cohort data using the approach of Meghir and Pistaferri (2004) building upon previous work on US data by Deaton and Paxson (1998). They find permanent income shocks lead to increased spending on tobacco and alcohol. Apouey and Clark (2011) also use UK data and evaluate the impact of lottery wins on health behaviours. They show that those who win larger amounts in lotteries exhibit no better general health compared with those winning small amounts, but do increase the number of cigarettes they smoke per day and frequency of alcohol consumption. Ruhm also finds that smoking and alcohol consumption are negatively related to the local unemployment rate.

We estimate the impact of county house prices on smoking intensity and the frequency of social drinking using the same modelling approach as that used in previous sections, again based on Equation 1a. In the BHPS, respondents that are current smokers ( $24 \%$ of the individual-year observations) are asked the approximate number of cigarettes smoked per day. We suppose usual consumption to be defined on a period at most over the past year. 
All individuals in the survey are also asked about the frequency of their social drinking in one of a succession of questions that ask about things people do in their leisure time. From the question: "How frequently do you go for a drink at a pub or club?" individuals can choose any of the following: "At least once a week; At least once a month; Several times a year; Once a year or less; Never/almost never" ${ }^{21}$. Approximately $72 \%$ of respondents engage in social drinking at least once per week. Results are shown in Table 8. The smaller sample size for the smoking intensity estimates reflects only $25 \%$ of our sample being smokers. The smaller sample size for the social drinking frequency estimates is due to the question on social drinking frequency occurring only in a limited number of waves of the survey $^{22}$.

We find a near identical relationship between the local unemployment rate and cigarettes per day to that found by Ruhm (2000) who also uses cigarettes per day as a measure of smoking intensity. The coefficient in our data on the local unemployment rate of 0.079 , which with a standard error of 0.046 is statistically significant at the $10 \%$ level and is comparable to the estimated coefficient of -0.0810 statistically significant at the $5 \%$ level in $\operatorname{Ruhm}(2000)^{23}$.

We find no relationship between the local unemployment rate and frequency of social drinking, in contrast to Ruhm (2000), though our social drinking variable differs from the general alcohol consumption variable used in his analysis in that it captures only 'social drinking' which might incorporate aspects of behaviour both positive to health (social leisure time) and negative to health (alcohol consumption, though the effects of alcohol consumption on health are less clear than the effects of smoking on health).

\footnotetext{
${ }^{21}$ The BHPS does not question respondents about alcohol consumption per se and this measure of 'social drinking frequency' is the only indication of the extent of alcohol consumption among respondents in the survey, also used in Apouey and Clark (2011).

${ }^{22}$ The question was included in the years 1996, 1998, 2000, 2002, 2004, 2006 and 2008 only.

${ }^{23}$ Table VI, p.641.
} 
Local house prices have no impact on cigarette consumption for either owners or renters in our data. The coefficient on the owner county house price variable is negative and differs from the positive coefficient on the renter county house price variable, but both are highly statistically insignificant and hence show no effect. The coefficient on the owner house price variable in the regression for social drinking frequency is positive and weakly significant at the 5\% level, but not statistically significantly different from the positive coefficient on the renter county house price variable. Any weak effect on social drinking arising from county house prices is not attributable to a causal impact on home owner behaviour. Hence overall we find no impact of home equity gains on smoking intensity or our measure of alcohol consumption.

Why do our findings for health behaviours differ from those in recent studies using UK data by Apouey and Clark (2011) and Adda et al. (2009)? We suggest the following possibilities. First, a major difference between our study and Apouey and Clark (2011) is that their wealth measure is lottery wins. Their study is based on a sample of lottery winners and it is very likely that participation into lottery proxies for lower-than-average risk aversion. There is therefore a third omitted variable in their analysis, namely degree of risk aversion, that is positively correlated with lottery participation (which in turn, increases the probability of winning) and with risky health behaviours. By contrast, our sample of house price movements is representative of the overall population and therefore less affected by selection issues. Second, Adda et al. (2009) study focuses on income innovations and it is possible that the positive effect of income shocks on risky health behaviours reflects the same outcomes seen in Ruhm's studies whereby higher income, reflecting increased incentives to work, leads to higher levels of stress-relief consumption such as smoking and drinking. 


\section{Conclusion}

The modern literature on the business cycle dynamics of health centres upon the seminal contributions of Christopher Ruhm. In a series of studies, Ruhm shows that individual health is negatively related to the local unemployment rate: counter to received wisdom, health actually worsens when the labour market improves. This finding for the way health responds to the local labour market has been interpreted as showing the impact of the business cycle on individual health.

In this paper, we have shown that pro-cyclical local labour market upturns are only one aspect of the business cycle dynamics of health: pro-cyclical movement in house prices and home equity generate strong impacts of individual health, health care usage, physical leisure and exercise which are as strong as the effects of labour market upturns. The key conclusion of our analysis is that the business cycle dynamics of health are driven by a combination of pro-cyclical and counter-cyclical health drivers and are more complex than the existing literature portrays. Our study further demonstrates the importance of home equity for household behaviour and welfare and the widespread consequences of house price volatility over the business cycle.

We show a broad range of health conditions decrease with home equity including common conditions relating to arthritic / rheumatic disorders, chest and respiratory problems plus heart and blood pressure. Effects are stronger for younger compared with older individuals and stronger for women than men. We show these effects occur in part through the normal channel of increased usage of health care, but also through the same channels by which local labour market conditions impact on health: hours of work, leisure and physical activity. Notably, the lack of strong effects of home equity on cigarette and alcohol consumption suggest these risky health behaviours are not normal good per se, but are particularly associated with labour income and work activity over the business cycle. 
Our results naturally raise the question of whether home equity effects on individual health might be found in US microdata, in particular data which includes the period of the US housing boom and bust of recent years, and how their magnitude would compare with the effect of local labour market conditions. Ruhm's studies are all based on data before the US house price boom, focusing on the period from the 1980s and 1990s during which there was no nationwide house price cycle in the US, unlike the UK which experienced house price cycles in the mid-1990s and again in the late 2000s.

More research on US data is needed, especially given the widespread purchase of private healthcare either via insurance or out-of-pocket expenses which might be more responsive to home equity gains compared with private purchases in the UK. More research is also needed to uncover the channels through which home equity gains impact on individual health. Also, in this study our data has not allowed us to examine other channels which are also shown to be important in Ruhm's. 


\section{References}

Adams P., Hurd M. D., McFadden D., Merrill A. and Ribeiro T. (2003). Healthy, wealthy, and wise? Tests for direct causal paths between health and socioeconomic status. Journal of Econometrics, 112: 3-56.

Adda, L., Banks, J. and von Gaudecker, H.M. (2009). The impact of income shocks on health: evidence from cohort data. Journal of the European Economic Association, 7: $1361-1399$.

Apouey, B. and Clark, A. (2011) Winning big but feeling no better? The effect of lottery prizes on physical and mental health. Working paper, Paris School of Economics.

Attanasio, O., Leicester, A. and Wakefield, M. (2011) The coincident cycles of house prices and consumption in the UK. Journal of the European Economic Association, 9: 399435.

Banks, J., Blundell, R. and Smith, J. P. (2003). Understanding differences in household financial wealth between the United States and Great Britain. Journal of Human Resources, 38: 241-79.

Besley T., Hall J. and Preston I., (1999). The demand for private health insurance: do waiting lists matter? Journal of Public Economics, 71:155-181.

Biddle J.E. and Hamermesh D.S. (1990). Sleep and the allocation of time, Journal of Political Economy, 95(5): 922-943.

Brunner, Eric J. (1997). Stress and the biology of inequality. British Medical Journal, 314, $1472-1476$.

Campbell, J. and Cocco, J.F. (2007). How do house prices affect consumption? Journal of Monetary Economics, 54: 591-621. 
Case A. (2004). Does money protect health status? Evidence from South African pensions. In Perspectives in the Economics of Aging, Wise D (ed.). University of Chicago Press: Chicago; 287-311.

Chou S.Y., Grossman M. and Saffer H., (2004). An economic analysis of adult obesity: results from the behavioural risk factor surveillance system. Journal of Health Economics, 23: 565-587.

Courbage C. and de Coulon A. (2004) Prevention and private health insurance in the U.K. The Geneva Papers on Risk and Insurance, 29: 719-727.

Courtemanche C. (2009). Longer hours and larger waistlines? The relationship between work hours and obsesity. Forum of Health Economics and Policy, 12: Art.2.

Crossley, T. and Kennedy, S. (2002). The reliability of self-assessed health status. Journal of Health Economics, 21: 643-658.

Currie, J., and Stabile, M. (2003). Socio-Economic status and child health: Why is the relationship stronger for older children? American Economic Review, 93: 1813-1823.

Currie, J. and Tekin, E. (2011). Is the foreclosure crisis making us sick? NBER Working Paper No. 17310.

Davidoff, F. (2010). Home equity commitment and long-term care insurance demand. Journal of Public Economics, 94: 44-49.

Deaton, A.S., Paxson, C.H. (1999). Mortality, education, income, and inequality among American cohorts. NBER Working Paper No. W7140.

Dehejia, R., and Muney, A.L. (2004). Booms, busts, and babies' health. Quarterly Journal of Economics; 119: 1091-1130.

Disney, R., Gathergood, J. and Henley, A. (2010) House price shocks, negative equity and household consumption in the United Kingdom. Journal of the European Economic Association, 8: 1179-1207. 
Edwards R., (2008). American time use over the business cycle, mimeo Queens College, August.

Ettner, S. (1996) New evidence on the relationship between income and health. Journal of Health Economics, 15: 67-86.

Farnham, M., Schmidt, L and Sevak, P. (2011) House prices and marital stability. American Economic Review, 101: 615-619.

Frijters, P., Haisken-DeNew, J.P., and Shields, M.A. (2005) The causal effect of income on health: evidence from German reunification. Journal of Health Economics, 24: 9971017.

Gardner J. and Oswald A. (2007) Money and mental wellbeing: a longitudinal study of medium-sized lottery wins. Journal of Health Economics, 26: 49-60.

Gathergood, J. (2012) Debt and depression: causal links and social norm effects. Economic Journal, 122: 1094-1114.

Grossman M. (1972). On the concept of health capital and the demand for health. Journal of Political Economy, 80: 233-255.

Hurst, E. and Stafford, F. (2004) Home is where the equity is: mortgage refinancing and household consumption. Journal of Money, Credit and Banking, 36: 987-1014.

Johansson E., (2003). A note on the impact of hours worked o n mortality in the OECD. The research Institute of the Finnish Economy Discussion Paper No. 878.

Kim, B and Ruhm, C. (2012) Inheritances, health and death. Health Economics, 21: 127-144.

Lindahl, M. (2005) Estimating the effect of income on health using lottery prizes as exogenous source of variation in income. Journal of Human Resources, 40: 144-168.

Lovenheim, M. and Mumford, K. (2012) Do family wealth shocks affect fertility choices: evidence from the housing market. Review of Economics and Statistics, forthcoming. 
Lovenheim, M. and Reynolds, C.L. (2011) The effect of short-term credit constraints on college choice: evidence from the housing boom. Mimeo.

Lovenheim, F. (2011) The effect of liquid housing wealth on college enrolment. Journal of Labor Economics, 29: 741-771.

Marmot, M., Bobak, M. (2000). International comparators and poverty and health in Europe. British Medical Journal; 321: 1124-1128.

Meer, J., Miller, D. and Rosen, H. (2003) Exploring the health-wealth nexus. Journal of Health Economics, 22: 713-730.

Meghir, C. and Pistaferri, L. (2004) Income variance dynamics and heterogeneity. Econometrica, 72: 1-32.

Mian, A. and Sufi, A. (2011) House Prices, Home Equity-Based Borrowing, and the U.S. Household Leverage Crisis. American Economic Review, 101: 2132-2156.

Michaud P-C, van Soest A. (2008). Health and wealth of elderly couples: causality tests using dynamic data and panel models. Journal of Health Economics, 27: 1312-1325.

Miller, D., Page, M.E., Stevens, A.H. and Filipski, M. (2009). Why are recessions good for your health? American Economic Review, 99: 122-127.

Petersen, A. and Pedersen, B. (2004). The anti-inflammatory effect of exercise. Journal of Applied Physiology, 98: 1154-1162.

Propper C., Rees H. and Green K. (2001). The demand for private medical insurance in the UK: a cohort analysis. Economic Journal, 111:C180-C200.

Reinold, K. (2011). Housing equity withdrawal since the financial crisis, Bank of England Quarterly Bulletin No. 2011 Q2.

Ruhm, C. (2000) Are recessions good for your health? Quarterly Journal of Economics, 115: 617-650. 
Ruhm, Christopher J., (2003). Good Times Make You Sick. Journal of Health Economics, 22: 637-658.

Ruhm, C. (2005). Healthy living in hard times. Journal of Health Economics, 24: 341-363.

Schwandt H. (2011). Wealth shocks and health outcomes: evidence from stock market fluctuations. Working paper available at: http://www.econ.upf.edu/jobmarket/pdf/paper/JMP Schwandt.pdf.

Smith, J. (1999) Healthy bodies and thick wallets: The dual relation between health and economic status. Journal of Economic Perspectives, 13: 145-166.

Snyder SE, Evans WN. (2006). The effect of income on mortality: evidence from the social security notch, Review of Economics and Statistics, 88: 482-495.

Sparks K. and Cooper C., (1997). The effects of work hours on health: a meta-analytic review. Journal of Occupational and Organizational Psychology, 70: 391-408.

Spivey A., (2010). Lose sleep, gain weight: another piece of the obesity puzzle. Environ Health Perspect. 118: A28-A33.

Van den Berg, G.J., Lindeboom, M. and Portrait, F. (2006). Economic conditions early in life and individual mortality. American Economic Review, 96: 290-302.

Williamson, J. and Pahor, M. (2010). Evidence regarding the benefits of physical exercise. Archives of Internal Medicine, 170: 124-125. 
Figure 1: Business Cycle Dynamics of House Prices and GDP in the UK, 1975-2012

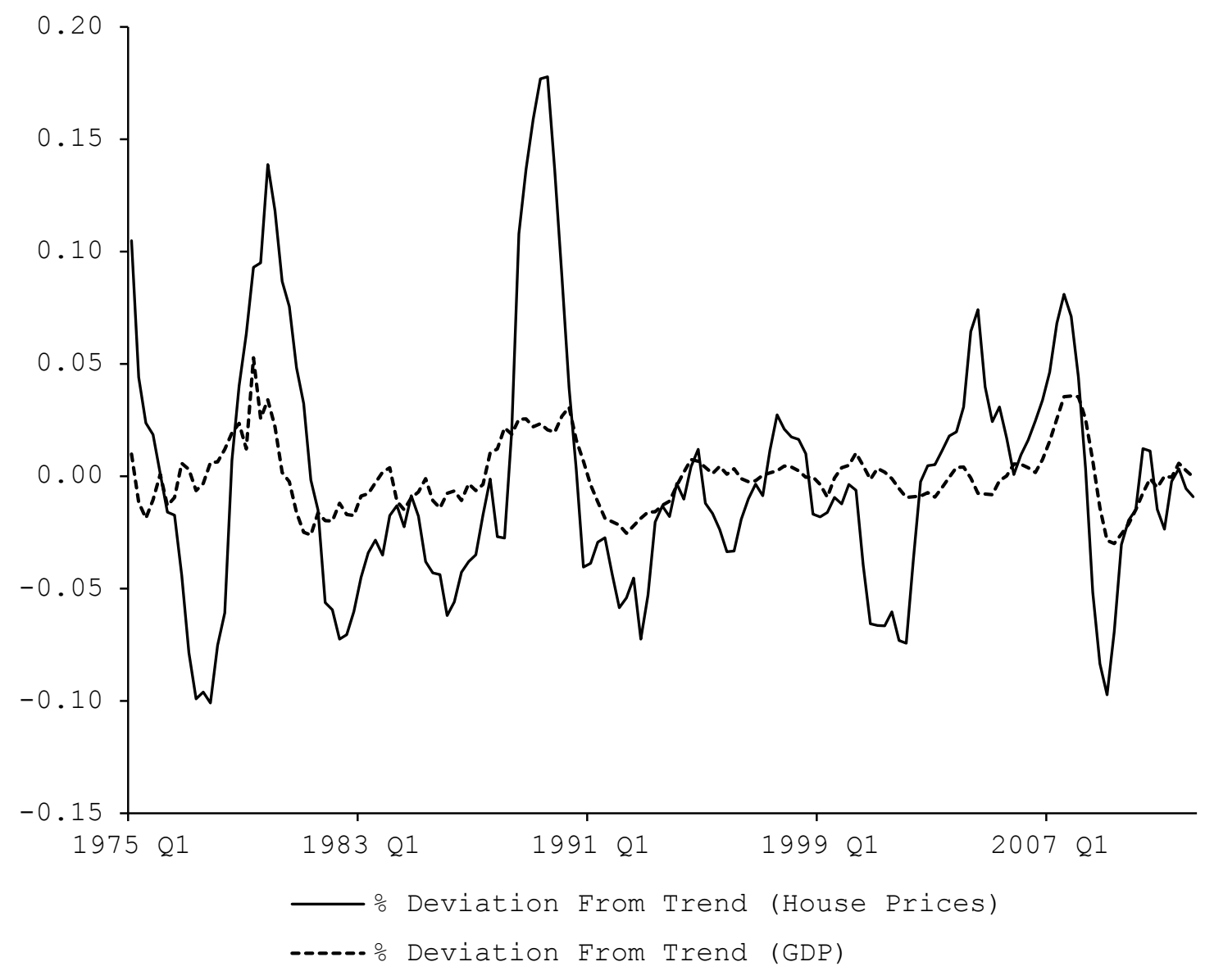

Figure shows percentage deviation from trend for UK house prices (Halifax quarterly standardised house price index, seasonally adjusted, Q1 1975 - Q2 2012) and Real Gross Domestic Product (chain weighted measure, ONS coded ABMI, Q1 1975 - Q2 2012). Deviations from trend are calculated by applying Hodrick-Prescott Filter to quarterly data $(\lambda=1600)$. 
Table 1

Summary Statistics for Demographics

and Socio-Economic Characteristics

Demographics

$\mathrm{N}$

155,396

Age (years)

51.1

Male

0.56

Ethnic Minority

0.15

Married

0.75

Divorced

0.08

Widowed

0.09

Children 0-2

0.07

Children 3-4

0.07

Children 5-11

0.27

Children 12-15

0.16

Children 16-18

0.04

Highest Educational Qualification

Degree

0.12

A-levels

0.15

O-levels

0.28

HND

0.07

Current Employment Status

Employed

0.49

Self-Employed

0.08

Unemployed

0.03

Retired

0.26

Household annual income

$£ 33,500$

Housing Status and House Value

Owner

0.78

Renter

0.22

House Value (£, owners,)

$£ 117,000$

Mortgage Value ( $£$, if value $>0$ )

$£ 53,300$

All financial variables at year 2000 prices, adjusted using RPI-X. 


\begin{tabular}{lc}
\hline \multicolumn{1}{c}{ Table 2 } \\
Summary Statistics for Health Conditions and Behaviours \\
\hline Health index (0-13) \\
Number of health conditions \\
Individual medical conditions (1/0) \\
Arms, legs, hands, feet, back, neck & 1.18 \\
Heart, blood pressure & 0.31 \\
Chest, respiratory & 0.19 \\
Skin & 0.13 \\
Hearing & 0.11 \\
Anxiety & 0.10 \\
Migraine, frequent headaches & 0.08 \\
Stomach, liver, kidneys & 0.08 \\
Sight & 0.08 \\
Diabetes & 0.06 \\
Cancer & 0.04 \\
Stroke & 0.02 \\
Epilepsy & 0.02 \\
Alcohol, drugs & 0.01 \\
Health behaviours & 0.01 \\
Smoker & \\
Number of cigarettes per day (if > 0) & 0.24 \\
Social Drinker (at least once per week) & 15.9 \\
Private medical coverage & 72.1 \\
Has private medical coverage & \\
\hline
\end{tabular}

Notes: The specific physical health conditions listed on the showcard shown to respondents are: i) Problems or disability connected with: arms, legs, hands, feet back, or neck (including arthritis and rheumatism); ii) Difficulty in seeing (other than needing glasses to read normal size print; iii) Difficulty in hearing; (iv) Skin conditions/allergies; (v) Chest/breathing problems, asthma, bronchitis; (vi) Heart/high blood pressure or blood circulation problems; (vii) Stomach/liver/kidneys or digestive problems; (viii) Diabetes; (ix) Anxiety, depression or bad nerves, psychiatric problems; (x) Alcohol or drug related problems; (xi) Epilepsy; (xii) Migraine or frequent headaches; (xiii) Cancer; (xiv) Stroke. An additional category (xv) 'Other' is also offered and 5\% of respondents choose this category. We omit the 'other' and 'anxiety, depression or bad nerves, psychiatric problems' from our analysis. 


\begin{tabular}{|c|c|c|c|c|c|c|c|}
\hline \multicolumn{8}{|c|}{$\begin{array}{c}\text { Table } 3 \\
\text { House Prices and Health } \\
\text { Cross-Section Estimates for Owners }\end{array}$} \\
\hline & $\begin{array}{l}\text { Arms, } \\
\text { legs } \\
\text { hands, } \\
\text { feet }\end{array}$ & Sight & Hearing & Skin & Chest & Heart & Stomach \\
\hline $\begin{array}{l}\text { House Value } \\
(£ 00,000 \text { s }) \\
\text { No. Obs. } \\
\mathrm{R}^{2}\end{array}$ & $\begin{array}{c}-0.008 * * \\
(0.001) \\
125,184 \\
0.13\end{array}$ & $\begin{array}{c}-0.003 * * \\
(0.001) \\
125,184 \\
0.05\end{array}$ & $\begin{array}{c}-0.006^{* *} \\
(0.001) \\
125,184 \\
0.09\end{array}$ & $\begin{array}{c}0.001 \\
(0.001) \\
125,184 \\
0.01\end{array}$ & $\begin{array}{c}-0.008 * * \\
(0.001) \\
125,184 \\
0.01\end{array}$ & $\begin{array}{c}-0.005^{* *} \\
(.001) \\
125,184 \\
0.17\end{array}$ & $\begin{array}{c}-0.003 * * \\
(0.001) \\
125,184 \\
0.01\end{array}$ \\
\hline $\mathrm{R}^{2}$ & Diabetes & Alcohol & Epilepsy & Migraine & Anxiety & Stroke & Cancer \\
\hline $\begin{array}{l}\text { House Value } \\
(£ 00,000 s) \\
\text { No. Obs. } \\
\mathrm{R}^{2}\end{array}$ & $\begin{array}{c}-0.002 * * \\
(0.001) \\
125,184 \\
0.02\end{array}$ & $\begin{array}{c}-0.001 * * \\
(0.000) \\
125,184 \\
0.01\end{array}$ & $\begin{array}{c}0.001 \\
(0.001) \\
125,184 \\
0.01\end{array}$ & $\begin{array}{c}-0.004 * * \\
(0.001) \\
125,184 \\
0.01\end{array}$ & $\begin{array}{c}-0.005 * * \\
(0.001) \\
125,184 \\
0.02\end{array}$ & $\begin{array}{c}-0.001 \\
(0.001) \\
71,091 \\
0.01\end{array}$ & $\begin{array}{c}0.001 \\
(0.001) \\
71,091 \\
0.02\end{array}$ \\
\hline
\end{tabular}

Notes: ** denotes statistical significance at 1\% level, * at 5\% level. Standard errors in parenthesis. Additional control variables: dummy variables for age bands (5 year intervals), ethnic minority status; marital status (married / with partner, divorced, widowed; omitted group: single); highest educational qualification (degree, A-level or equivalent, O-level or equivalent, HND or equivalent; omitted group: no qualifications); number of children aged 0-3, 4-5, 6-12, 13-16; household monthly gross income (£). 


\section{Table 4}

House Prices and Health

Panel Estimates with Renters Comparison

\begin{tabular}{|c|c|c|c|c|c|c|}
\hline & Count & $\begin{array}{c}\text { Arms, } \\
\text { legs } \\
\text { hands, } \\
\text { feet }\end{array}$ & Sight & Skin & Chest & Heart \\
\hline $\begin{array}{l}\text { 1.County House Price } \\
\text { - Owners }(£ 00,000 \mathrm{~s})\end{array}$ & $\begin{array}{c}-0.158 * * \\
(0.019)\end{array}$ & $\begin{array}{c}-0.023 * * \\
(0.008)\end{array}$ & $\begin{array}{l}-0.001 \\
(0.006)\end{array}$ & $\begin{array}{c}-0.020 * * \\
(0.005)\end{array}$ & $\begin{array}{c}-0.037 * * \\
(0.005)\end{array}$ & $\begin{array}{c}-0.025 * * \\
(0.006)\end{array}$ \\
\hline 2.County House Price & -0.013 & 0.003 & $0.017 * *$ & $0.012 *$ & 0.004 & -0.010 \\
\hline - Renters $(£ 00,000 \mathrm{~s})$ & $(0.022)$ & $(0.009)$ & $(0.006)$ & $(0.006)$ & $(0.005)$ & $(0.007)$ \\
\hline 3. Unem. Rate (\%) & $\begin{array}{c}-0.014 * * \\
(0.004)\end{array}$ & $\begin{array}{c}-0.003^{* *} \\
(0.001)\end{array}$ & $\begin{array}{c}0.001 \\
(0.001)\end{array}$ & $\begin{array}{c}-0.004 * * \\
(0.001)\end{array}$ & $\begin{array}{l}-0.001 \\
(0.001)\end{array}$ & $\begin{array}{c}0.001 \\
(0.001)\end{array}$ \\
\hline No. Obs. & 155,396 & 155,396 & 155,396 & 155,396 & 155,396 & 155,396 \\
\hline No. Groups & 18,645 & 18,645 & 18,645 & 18,645 & 18,645 & 18,645 \\
\hline \multirow[t]{2}{*}{ Test $1=2$ (p-value) } & 0.0000 & 0.0000 & 0.0000 & 0.0659 & 0.0000 & 0.0005 \\
\hline & Diabetes & Alcohol & Epilepsy & Anxiety & Stroke & Cancer \\
\hline $\begin{array}{l}\text { 1. County House Price } \\
\text { - Owners }(£ 00,000 \mathrm{~s})\end{array}$ & $\begin{array}{c}-0.010 * * \\
(0.002)\end{array}$ & $\begin{array}{c}-0.002 * * \\
(0.001)\end{array}$ & $\begin{array}{c}-0.003 * * \\
(0.001)\end{array}$ & $\begin{array}{c}-0.030 * * \\
(0.004)\end{array}$ & $\begin{array}{c}-0.013^{*} \\
(0.006)\end{array}$ & $\begin{array}{l}-0.001 \\
(0.006)\end{array}$ \\
\hline 2. County House Price & $\begin{array}{c}0.004 \\
(0.003)\end{array}$ & $\begin{array}{c}0.002 \\
(0.001)\end{array}$ & $\begin{array}{l}-0.002 \\
(0.002)\end{array}$ & $\begin{array}{l}-0.019 * * \\
(0.005)\end{array}$ & $\begin{array}{l}-0.004 \\
(0.007)\end{array}$ & $\begin{array}{l}-0.003 \\
(0.007)\end{array}$ \\
\hline 3. Unem. Rate $(\%)$ & $\begin{array}{c}-0.002 * * \\
(0.001)\end{array}$ & $\begin{array}{l}-0.001 \\
(0.001)\end{array}$ & $\begin{array}{l}-0.001 \\
(0.001)\end{array}$ & $\begin{array}{c}0.001 \\
(0.001)\end{array}$ & $\begin{array}{c}-0.003 * * \\
(0.001)\end{array}$ & $\begin{array}{c}0.001 \\
(0.001)\end{array}$ \\
\hline No. Obs. & 155,396 & 155,396 & 155,396 & 155,396 & 74,974 & 74,974 \\
\hline No. Groups & 18,645 & 18,645 & 18,645 & 18,645 & 13,301 & 13,301 \\
\hline Test $1=2$ (p-value) & 0.0000 & 0.0002 & 0.3258 & 0.0049 & 0.0852 & 0.6949 \\
\hline
\end{tabular}

Notes: ** denotes statistical significance at $1 \%$ level, * at 5\% level. Cluster (county-level) standard errors in parenthesis. Additional control variables: dummy variables for age bands (5 year intervals), marital status (married / with partner, divorced, widowed; omitted group: single); highest educational qualification (degree, A-level or equivalent, $O$-level or equivalent, $H N D$ or equivalent; omitted group: no qualifications); number of children aged 0-3, 4-5, 6-12, 13-16; household monthly gross income (£). 


\begin{tabular}{|c|c|c|c|c|c|}
\hline \multicolumn{6}{|c|}{$\begin{array}{c}\text { Table 5 } \\
\text { House Prices and Health } \\
\text { ects From House Prices and Local Unemployment Rate }\end{array}$} \\
\hline \multirow[b]{2}{*}{ Health Variable } & \multirow[b]{2}{*}{$\begin{array}{l}\text { Mean in } \\
\text { Sample of } \\
\text { Owners }\end{array}$} & \multicolumn{2}{|c|}{ Local House Prices } & \multicolumn{2}{|c|}{ Local Unemployment Rate } \\
\hline & & $\begin{array}{l}\text { Coefficient in } \\
\text { Table } 4\end{array}$ & $\begin{array}{l}\% \text { Change } \\
\text { From 1 S.D. } \\
\text { Increase }\end{array}$ & $\begin{array}{l}\text { Coefficient } \\
\text { in Table } 4\end{array}$ & $\begin{array}{l}\% \text { Change } \\
\text { From } 1 \text { S.D. } \\
\text { Increase }\end{array}$ \\
\hline Count & 1.18 & $-0.158 * *$ & $-6.7 \%$ & $-0.014 * *$ & $-3.4 \%$ \\
\hline Arms, legs, hands feet & 0.29 & $-0.023 * *$ & $-3.9 \%$ & $-0.003 * *$ & $-2.9 \%$ \\
\hline Skin & 0.11 & $-0.020 * *$ & $-9.1 \%$ & $-0.004 * *$ & $-10.5 \%$ \\
\hline Chest & 0.11 & $-0.037 * *$ & $-16.8 \%$ & -0.001 & - \\
\hline Heart & 0.18 & $-0.025 * *$ & $-6.9 \%$ & 0.001 & - \\
\hline Diabetes & 0.04 & $-0.010 * *$ & $-12.5 \%$ & $-0.002 * *$ & $-14.4 \%$ \\
\hline Alcohol & 0.01 & $-0.002 * *$ & $-10.0 \%$ & -0.001 & - \\
\hline Epilepsy & 0.01 & $-0.003 * *$ & $-15.0 \%$ & -0.001 & - \\
\hline Anxiety & 0.07 & $-0.030 * *$ & $-21.4 \%$ & 0.001 & - \\
\hline Stroke & 0.02 & $-0.013^{*}$ & $-32.5 \%$ & $-0.002 * *$ & $-28.8 \%$ \\
\hline
\end{tabular}

Notes: Table shows implied percentage change in health variable measures from a one standard deviation in local house prices and the local unemployment rate based on the estimated coefficient from Table 4. The standard deviation of local house prices among owners in the sample is $£ 49,000$ and the standard deviation of the local unemployment rate among owners in the sample is 2.88 percentage points. Where the estimated coefficient from the models in Table 4 is statistically not significant at the 5\% level or lower the implied \% change in the outcome variable is not shown and is designated ' - . No results are shown for the 'sight' category or the 'cancer' category as neither the coefficient on the house price term or the unemployment rate were significant 


\section{House Prices and Health \\ Predicted Effects By Age}

Young (aged 59 or below)

Local House Prices

Health Variable

\begin{abstract}
Mean in
Sample of

Owners
\end{abstract}

\author{
$\%$ Change \\ From 1 S.D. \\ Increase
}

Local Unemployment Rate

\section{Coefficient}

in Panel

Estimate
$\%$ Change

From 1 S.D.

Increase

\begin{tabular}{lccccc} 
Count & 0.82 & $-0.152^{* *}$ & $-6.2 \%$ & $-0.021 * *$ & $-7.4 \%$ \\
Arms, legs, hands feet & 0.21 & $-0.023^{* *}$ & $-5.5 \%$ & $-0.008^{* *}$ & $-10.9 \%$ \\
Skin & 0.12 & $-0.014^{*}$ & $-5.8 \%$ & $-0.006 * *$ & $-14.4 \%$ \\
Chest & 0.09 & $-0.032^{* *}$ & $-17.8 \%$ & -0.001 & - \\
Heart & 0.09 & $-0.026^{* *}$ & $-14.4 \%$ & -0.001 & - \\
Stomach & 0.06 & -0.007 & - & $-0.004 * *$ & $-19.2 \%$ \\
Diabetes & 0.02 & $-0.006^{* *}$ & $-15.0 \%$ & -0.001 & - \\
Alcohol & 0.01 & $-0.003^{*}$ & $-15.0 \%$ & -0.001 & - \\
Epilepsy & 0.01 & $-0.004^{* *}$ & $-20.0 \%$ & -0.001 & - \\
Anxiety & 0.06 & $-0.031^{* *}$ & $-25.8 \%$ & 0.001 & - \\
Stroke & 0.01 & -0.008 & - & $-0.003 * *$ & $-37.4 \%$ \\
\hline
\end{tabular}

Old (age 60 or over)

Local House Prices Local Unemployment Rate

$\begin{array}{cccccc}\text { Health Variable } & \text { Mean in } & \text { Coefficient in } & \% \text { Change } & \text { Coefficient } & \% \text { Change } \\ & \text { Sample of } & \text { Panel } & \text { From 1 S.D. } & \text { in Panel } & \text { From 1 S.D. } \\ \text { Owners } & \text { Estimate } & \text { Increase } & \text { Estimate } & \text { Increase }\end{array}$

\begin{tabular}{lccccc} 
Count & 1.73 & $-0.109^{* *}$ & $-3.1 \%$ & 0.001 & - \\
Arms, legs, hands feet & 0.49 & $-0.030^{*}$ & $-3.1 \%$ & 0.004 & - \\
Skin & 0.10 & $-0.029^{*}$ & $-14.5 \%$ & 0.001 & - \\
Chest & 0.16 & -0.014 & - & 0.002 & - \\
Heart & 0.40 & -0.024 & - & 0.006 & - \\
Diabetes & 0.07 & -0.013 & - & -0.002 & - \\
Alcohol & 0.01 & 0.001 & - & -0.001 & - \\
Epilepsy & 0.01 & -0.001 & - & -0.001 & - \\
Anxiety & 0.07 & $-0.020^{*}$ & $-14.2 \%$ & $0.005^{* *}$ & $-3.6 \%$ \\
Stroke & 0.03 & -0.020 & - & -0.005 & - \\
\hline
\end{tabular}

Notes: Table shows implied percentage change in health variable measures from a one standard deviation in local house prices and the local unemployment rate based on the estimated coefficient from Table 4. The standard deviation of local house prices among owners in the sample is £49,000 and the standard deviation of the local unemployment rate among owners in the sample is 2.88 percentage points. Where the estimated coefficient from the models in Table 4 is statistically not significant at the 5\% level or lower the implied \% change in the outcome variable is not shown and is designated ' - . No results are shown for the 'sight' category or the 'cancer' category as neither the coefficient on the house price term or the unemployment rate were significant 


\begin{tabular}{|c|c|c|c|c|c|c|}
\hline \multicolumn{7}{|c|}{$\begin{array}{c}\text { Table } 7 \\
\text { House Prices and Health } \\
\text { Predicted Effects By Gender } \\
\end{array}$} \\
\hline \multirow[b]{2}{*}{ Health Variable } & \multicolumn{3}{|c|}{ Men } & \multicolumn{3}{|c|}{ Women } \\
\hline & $\begin{array}{l}\text { Mean in } \\
\text { Sample of } \\
\text { Male } \\
\text { Owners }\end{array}$ & $\begin{array}{l}\text { Coefficient } \\
\text { in Panel } \\
\text { Estimate }\end{array}$ & $\begin{array}{l}\% \text { Change } \\
\text { From } 1 \text { S.D. } \\
\text { Increase }\end{array}$ & $\begin{array}{l}\text { Mean in } \\
\text { Sample of } \\
\text { Female } \\
\text { Owners }\end{array}$ & $\begin{array}{l}\text { Coefficient } \\
\text { in Panel } \\
\text { Estimate }\end{array}$ & $\begin{array}{l}\text { \% Change } \\
\text { From } 1 \text { S.D. } \\
\text { Increase }\end{array}$ \\
\hline Count & 0.99 & $-0.071 * *$ & $-3.6 \%$ & 1.16 & $-0.229 * *$ & $-9.9 \%$ \\
\hline Arms, legs, hands... & 0.26 & $-0.026^{*}$ & $-5.0 \%$ & 0.32 & $-0.020 *$ & $-3.1 \%$ \\
\hline Skin & 0.10 & -0.012 & $-6.0 \%$ & 0.12 & $-0.026 * *$ & $-10.8 \%$ \\
\hline Chest & 0.11 & $-0.036^{* *}$ & $-16.4 \%$ & 0.11 & $-0.038 * *$ & $-17.3 \%$ \\
\hline Heart & 0.18 & 0.001 & - & 0.18 & $-0.044 * *$ & $-12.2 \%$ \\
\hline Diabetes & 0.04 & $-0.009^{*}$ & $-11.3 \%$ & 0.03 & $-0.009 * *$ & $-15.0 \%$ \\
\hline Alcohol & 0.01 & $-0.003 *$ & $-15.0 \%$ & 0.01 & -0.002 & - \\
\hline Epilepsy & 0.01 & -0.001 & - & 0.01 & $-0.005 * *$ & $-25.0 \%$ \\
\hline Stroke & 0.02 & -0.014 & - & 0.02 & -0.014 & - \\
\hline Anxiety & 0.04 & -0.004 & - & 0.09 & $-0.052 * *$ & $-28.8 \%$ \\
\hline Cancer & 0.03 & -0.002 & - & 0.06 & 0.007 & - \\
\hline
\end{tabular}

Notes: Table reports estimated coefficients and standard errors on the home owner house price variable in separate regressions for each health outcome estimated in separate samples for each group (men, women, older, young).** denotes statistical significance at $1 \%$ level, * at $5 \%$ level. Standard errors in parenthesis. Additional control variables: dummy variables for age bands (5 year intervals), marital status (married / with partner, divorced, widowed; omitted group: single); highest educational qualification (degree, A-level or equivalent, O-level or equivalent, HND or equivalent; omitted group: no qualifications); number of children aged 0-3, 4-5, 6-12, 13-16; household monthly gross income (£). 


\section{Table 8}

House Prices and Private Medical Coverage

Panel Estimates

\begin{tabular}{lccccc}
\hline & All & Women & Men & Young & Old \\
& & & & & \\
1. County House Price & $0.020^{* *}$ & $0.017 * *$ & $0.023^{* *}$ & $0.040^{* *}$ & 0.006 \\
$\quad$ - Owners (£00,000s) & $(0.004)$ & $(0.004)$ & $(0.006)$ & $(0.008)$ & $(0.005)$ \\
2. County House Price & -0.003 & -0.002 & -0.005 & 0.013 & -0.008 \\
$\quad$ - Renters $(£ 00,000 \mathrm{~s})$ & $(0.004)$ & $(0.005)$ & $(0.006)$ & $(0.008)$ & $(0.005)$ \\
3. Unem. Rate (\%) & -0.001 & 0.001 & -0.001 & 0.002 & -0.001 \\
& $(0.001)$ & $(0.001)$ & $(0.001)$ & $(0.001)$ & $(0.001)$ \\
No. Obs. & 155,396 & 84,022 & 69,903 & 75,300 & 85,096 \\
No. Groups & 18,645 & 9,585 & 8,458 & 6,260 & 14,096 \\
Test 1=2 (p-value) & 0.0000 & 0.0000 & 0.0000 & 0.0000 & 0.0000 \\
\hline
\end{tabular}

Notes: ** denotes statistical significance at 1\% level, * at 5\% level. Cluster (county level) standard errors in parenthesis. Additional control variables: dummy variables for age bands (5 year intervals), marital status (married / with partner, divorced, widowed; omitted group: single); highest educational qualification (degree, A-level or equivalent, O-level or equivalent, HND or equivalent; omitted group: no qualifications); number of children aged 0-3, 4-5, 6-12, 13-16; household monthly gross income (£). 


\begin{tabular}{|c|c|c|c|c|c|c|}
\hline \multicolumn{7}{|c|}{$\begin{array}{c}\text { Table } 9 \\
\text { House Prices and Hours of Work and Re } \\
\text { Panel Estimates }\end{array}$} \\
\hline & \multicolumn{2}{|c|}{$\begin{array}{l}\text { Typical Hours of } \\
\text { Work Per Week }\end{array}$} & \multicolumn{2}{|c|}{$\begin{array}{l}\text { Sport or Exercise At } \\
\text { Least Once A Week }\end{array}$} & \multicolumn{2}{|c|}{$\begin{array}{l}\text { Health Limits Daily } \\
\text { Activities }\end{array}$} \\
\hline & Women & Men & Women & Men & Women & Men \\
\hline $\begin{array}{l}\text { 1. County House Price } \\
\text { - Owners }(£ 00,000 \mathrm{~s})\end{array}$ & $\begin{array}{c}-0.956 * * \\
(0.367)\end{array}$ & $\begin{array}{c}0.463 \\
(0.351)\end{array}$ & $\begin{array}{c}0.045^{* *} \\
(0.011)\end{array}$ & $\begin{array}{c}0.017 \\
(0.011)\end{array}$ & $\begin{array}{c}-0.033 * * \\
(0.009)\end{array}$ & $\begin{array}{c}-0.023 * * \\
(0.008)\end{array}$ \\
\hline 2. County House Price & $1.340 * *$ & $1.069 * *$ & 0.009 & -0.005 & 0.009 & -0.001 \\
\hline - Renters (£00,000s) & $(0.472)$ & $(0.427)$ & $(0.012)$ & $(0.013)$ & $(0.010)$ & $(0.011)$ \\
\hline 3. Unemployment Rate (\%) & $\begin{array}{l}-0.157 * \\
(0.068)\end{array}$ & $\begin{array}{c}-0.238 * * \\
(0.069)\end{array}$ & $\begin{array}{c}0.001 \\
(0.002)\end{array}$ & $\begin{array}{c}0.001 \\
(0.002)\end{array}$ & $\begin{array}{l}-0.002 \\
(0.002)\end{array}$ & $\begin{array}{c}0.001 \\
(0.002)\end{array}$ \\
\hline No. Obs. & 39,104 & 35,365 & 84,022 & 69,903 & 72,934 & 60,728 \\
\hline No. Groups & 5,869 & 5,338 & 9,585 & 8,458 & 9,273 & 8,156 \\
\hline Test $1=2(p$-value $)$ & 0.0000 & 0.0639 & 0.0000 & 0.0140 & 0.0000 & 0.0038 \\
\hline
\end{tabular}

Notes: ** denotes statistical significance at 1\% level, * at 5\% level. Cluster (county level) standard errors in parenthesis. Additional control variables: dummy variables for age bands (5 year intervals), marital status (married / with partner, divorced, widowed; omitted group: single); highest educational qualification (degree, A-level or equivalent, $O$-level or equivalent, HND or equivalent; omitted group: no qualifications); number of children aged 0-3, 4-5, 6-12, 13-16; household monthly gross income (£). 


\begin{tabular}{lcc}
\hline \multicolumn{3}{c}{ House Prices, Smoking and Drinking } \\
Panel Estimates \\
\hline & Cigarettes Per & Social Drinking \\
& Day & Frequency \\
& & \\
1. County House Price & -0.126 & $0.067 *$ \\
- Owners (£00,000s) & $(0.129)$ & $(0.032)$ \\
2. County House Price & 0.292 & 0.052 \\
- Renters (£00,000s) & $(0.251)$ & $(0.037)$ \\
3. Unemployment Rate $(\%)$ & -0.079 & 0.005 \\
& $(0.046)$ & $(0.007)$ \\
No. Obs. & 37,176 & 59,564 \\
No. Groups & 6,255 & 14,032 \\
Test 1=2 (p-value) & 0.0137 & 0.5792 \\
\hline
\end{tabular}

Notes: ** denotes statistical significance at 1\% level, * at 5\% level. Cluster (county level) standard errors in parenthesis. Additional control variables: dummy variables for age bands (5 year intervals), marital status (married / with partner, divorced, widowed; omitted group: single); highest educational qualification (degree, A-level or equivalent, $O$-level or equivalent, HND or equivalent; omitted group: no qualifications); number of children aged 0-3, 4-5, 6-12, 13-16; household monthly gross income (£). 


\begin{tabular}{|c|c|c|c|c|}
\hline \multicolumn{5}{|c|}{$\begin{array}{c}\text { Table A1: } \\
\begin{array}{c}\text { Home Moving and Health Changes } \\
\text { Panel Estimates for Owners }\end{array} \\
\end{array}$} \\
\hline & 1 & 2 & 3 & 4 \\
\hline & Moves & Moves Home to & Moves & Moves Home to \\
\hline & Home & Higher House & Home & Lower House \\
\hline & Between & Price County & Between & Price County \\
\hline & Waves & Between Waves & Waves & Between Waves \\
\hline & \multicolumn{2}{|c|}{ recovers from condition } & \multicolumn{2}{|c|}{ onset of condition } \\
\hline \multirow{3}{*}{ Arms, legs, hands, feet } & & & & \\
\hline & -0.004 & 0.001 & $-0.009 * *$ & $-0.010 * *$ \\
\hline & $(0.003)$ & $(0.001)$ & $(0.003)$ & $(0.003)$ \\
\hline \multirow[t]{2}{*}{ Sight } & -0.001 & 0.001 & -0.006 & -0.007 \\
\hline & $(0.004)$ & $(0.001)$ & $(0.004)$ & $(0.006)$ \\
\hline \multirow[t]{2}{*}{ Hearing } & -0.005 & -0.002 & -0.004 & -0.003 \\
\hline & $(0.004)$ & $(0.002)$ & $(0.004)$ & $(0.004)$ \\
\hline \multirow[t]{2}{*}{ Skin } & $-0.009 * *$ & 0.001 & 0.003 & 0.004 \\
\hline & $(0.004)$ & $(0.001)$ & $(0.004)$ & $(0.005)$ \\
\hline \multirow[t]{2}{*}{ Chest } & -0.004 & -0.001 & -0.002 & -0.002 \\
\hline & $(0.004)$ & $(0.001)$ & $(0.003)$ & $(0.003)$ \\
\hline \multirow[t]{2}{*}{ Heart } & $-0.007^{*}$ & 0.001 & -0.007 & -0.005 \\
\hline & $(0.004)$ & $(0.001)$ & $(0.004)$ & $(0.004)$ \\
\hline \multirow[t]{2}{*}{ Stomach } & -0.006 & -0.001 & -0.009 & -0.011 \\
\hline & $(0.004)$ & $(0.001)$ & $(0.009)$ & $(0.010)$ \\
\hline \multirow[t]{2}{*}{ Diabetes } & -0.001 & -0.001 & -0.001 & -0.002 \\
\hline & $(0.001)$ & $(0.001)$ & (0.004) & (0.004) \\
\hline \multirow[t]{2}{*}{ Alcohol } & -0.021 & 0.009 & 0.012 & 0.010 \\
\hline & (0.019) & (0.006) & $(0.019)$ & (0.019) \\
\hline \multirow[t]{2}{*}{ Epilepsy } & 0.001 & 0.006 & $-0.061^{*}$ & -0.052 \\
\hline & $(0.023)$ & $(0.007)$ & $(0.024)$ & $(0.024)$ \\
\hline \multirow[t]{2}{*}{ Migraine } & -0.005 & 0.001 & $-0.002 * *$ & $-0.002 * *$ \\
\hline & $(0.004)$ & $(0.001)$ & $(0.004)$ & $(0.004)$ \\
\hline \multirow[t]{2}{*}{ Cancer } & -0.008 & -0.001 & 0.001 & 0.002 \\
\hline & $(0.012)$ & $(0.004)$ & $(0.013)$ & $(0.013)$ \\
\hline \multirow[t]{2}{*}{ Stroke } & -0.002 & -0.002 & 0.001 & 0.003 \\
\hline & $(0.010)$ & $(0.003)$ & $(0.001)$ & $(0.003)$ \\
\hline No. Obs & 117,658 & 117,658 & 117,658 & 117,658 \\
\hline
\end{tabular}

Notes: ** denotes statistical significance at $1 \%$ level, * at 5\% level. Standard errors in parenthesis. Additional control variables: dummy variables for age bands (5 year intervals); marital status (married / with partner, divorced, widowed; omitted group: single); highest educational qualification (degree, A-level or equivalent, $O$ level or equivalent, HND or equivalent; omitted group: no qualifications); number of children aged 0-3, 4-5, 612, 13-16; household monthly gross income (£). 


\section{Table A2}

House Prices and Health

Panel Estimates - Non-Moving Individuals Only

\begin{tabular}{lcccccc} 
& Count & $\begin{array}{c}\text { Arms, legs } \\
\text { hands, feet }\end{array}$ & Sight & Skin & Chest & Heart \\
1. County House Price & $-0.164^{* *}$ & $-0.027 * *$ & -0.001 & $-0.021^{* *}$ & $-0.039^{* *}$ & $-0.026^{* *}$ \\
$\quad$ - Owners (£00,000s) & $(0.020)$ & $(0.008)$ & $(0.006)$ & $(0.005)$ & $(0.005)$ & $(0.006)$ \\
2. County House Price & -0.012 & 0.005 & $0.018^{* *}$ & $0.015^{*}$ & 0.004 & -0.011 \\
$\quad$ - Renters (£00,000s) & $(0.023)$ & $(0.010)$ & $(0.007)$ & $(0.007)$ & $(0.006)$ & $(0.007)$ \\
3. Unem. Rate (\%) & $-0.014 * *$ & $-0.004^{*}$ & 0.001 & $-0.004^{* *}$ & -0.001 & 0.001 \\
& $(0.004)$ & $(0.002)$ & $(0.001)$ & $(0.001)$ & $(0.001)$ & $(0.001)$ \\
No. Obs. & 147,356 & 147,356 & 147,356 & 147,356 & 147,356 & 147,356 \\
No. Groups & 17,072 & 17,072 & 17,072 & 17,072 & 17,072 & 17,072 \\
Test 1=2 (p-value) & 0.0000 & 0.0000 & 0.3477 & 0.0000 & 0.0000 & 0.0043 \\
& & & & & & \\
& & & & & & \\
& Diabetes & Alcohol & Epilepsy & Anxiety & Stroke & Cancer \\
& & & & & & \\
1. County House Price & $-0.008^{* *}$ & $-0.002^{*}$ & $-0.003 * *$ & $-0.030^{* *}$ & $-0.012 *$ & -0.001 \\
$\quad$ Owners (£00,000s) & $(0.003)$ & $(0.001)$ & $(0.001)$ & $(0.005)$ & $(0.006)$ & $(0.006)$ \\
2. County House Price & 0.006 & 0.003 & -0.002 & $-0.019^{* *}$ & -0.003 & -0.003 \\
$\quad$ Renters (£00,000s) & $(0.003)$ & $(0.002)$ & $(0.002)$ & $(0.006)$ & $(0.007)$ & $(0.007)$ \\
3. Unem. Rate (\%) & $-0.001 * *$ & -0.001 & -0.001 & 0.001 & $-0.003 * *$ & 0.001 \\
& $(0.001)$ & $(0.001)$ & $(0.001)$ & $(0.001)$ & $(0.001)$ & $(0.001)$ \\
No. Obs. & 147,356 & 147,356 & 147,356 & 147,356 & 71,691 & 71,691 \\
No. Groups & 17,072 & 17,072 & 17,072 & 17,072 & 12,361 & 12,361 \\
Test 1=2 (p-value) & 0.0000 & 0.0002 & 0.0385 & 0.0130 & 0.0680 & 0.8848 \\
\hline
\end{tabular}

Notes: ** denotes statistical significance at 1\% level, * at 5\% level. Cluster (county level) standard errors in parenthesis. Additional control variables: dummy variables for age bands (5 year intervals), marital status (married / with partner, divorced, widowed; omitted group: single); highest educational qualification (degree, A-level or equivalent, O-level or equivalent, HND or equivalent; omitted group: no qualifications); number of children aged 0-3, 4-5, 6-12, 13-16; household monthly gross income (£). 